\title{
Primary Biliary Cirrhosis in A Patient with Turner Syndrome
}

\author{
Yomna Dannouni $^{1 *}$, Sara Boulajaad ${ }^{1}$, Jihane Rizkou ${ }^{1}$, Adil Ait Errami ${ }^{1}$, Zouhour Samlani ${ }^{1}$, Sofia Oubaha ${ }^{2}$, Khadija
} $\mathrm{Krati}^{1}$

${ }^{1}$ Department of Gastroenterology, Mohamed VI University Hospital, Marrakech, Morocco

${ }^{2}$ Laboratory of Physiology, Cadi Ayyad University Faculty of Medicine and Pharmacy of Marrakech, Morocco

DOI: $10.36347 /$ sjmcr.2020.v08i05.017

| Received: 06.02.2020 | Accepted: 13.02.2020 | Published: 23.05.2020

*Corresponding author: Yomna Dannouni

\section{Abstract}

Turner's syndrome, the most common chromosome abnormality in females, is the consequence of complete absence or partial deletion of one X chromosome. It is associated with a wide spectrum of clinical features of which short stature and gonadal dysgenesis are almost invariably present. Women with Turner's syndrome are susceptible to a number of disorders including autoimmune diseases. A case of a primary biliary cirrhosis (PBC) in a patient with Turner's syndrome is presented. The individual was admitted for a 3 menth history of intermittent abdominal pain and progressive distension. Laboratory, radiology and endoscopic investigations confirmed the diagnosis of PBC with portal hypertension. The possible association of Turner's syndrome with primary biliary cirrhosis is here discussed with a review of the published literature.

Keywords: Turner's syndrome, chromosome, primary biliary cirrhosis (PBC).

Copyright @ 2020: This is an open-access article distributed under the terms of the Creative Commons Attribution license which permits unrestricted use, distribution, and reproduction in any medium for non-commercial use (NonCommercial, or CC-BY-NC) provided the original author and source are credited.

\section{INTRODUCTION}

Turner syndrome is one of the most frequent inherited diseases, with a prevalence of 1/2500 female live birth. It results from the total or partial loss of the $\mathrm{X}$ chromosome. Clinically, this syndrome is characterized by short stature, gonadal dysgenesia, dysmorphic features, congenital heart and renal malformations and predisposition to autoimmune diseases [1]. The clinical spectrum is very broad and it can be associated with hypothyroidism, autoimmune diseases, coarctation of the aorta, valvular heart disease, diabetes mellitus, etc. Certain genetic conditions predispose patients to liver disease, with some ultimately progressing to cirrhosis. Some with a relatively clear mechanism, whereas liver disease in Turner syndrome is not as well-elucidated. Steatosis, steatofibrosis and steatohepatitis are the most frequently reported lesions in Turner syndrome's patient, caused by metabolic disorders, which are commonly related to overweight. There have been few documented cases of liver cirrhosis in these patients. Here we present a case of a 25 years old women with Turner syndrome developed a liver cirrhosis.

\section{Case Presentation}

We present the case of a 25-year-old woman without any medical history (no alcohol consumption, smoking, or taking any medication) and there was no family history of note. She was referred to our gastroenterology department with a 3 menth history of intermittent abdominal pain and progressive distension with a primary amenorrhoea. She denied having choluria, acholia and haematemesis, as well as fever, night sweats, myalgia and weight loss. On examination, the patient appeared dehydrated, but she was haemodynamically stable and afebrile.

She was noted to be short in stature and had other phenotypic features of turner syndrome : short neck with a webbed appearance, Broad chest (shield chest) and widely spaced nipples, low hairline at the back of the neck, low-set ears, soft and small fingernails that turn upward and lack of secondary sex characteristic (Figure-1). Her abdomen was soft, but tender, without guarding or rebound. A large splenomegaly of $17 \mathrm{~cm}$ and no other masses were palpated. On percussion, a shifting dullness was observed, which suggested ascites. Examination revealed no peripheral stigmata of chronic liver disease. 


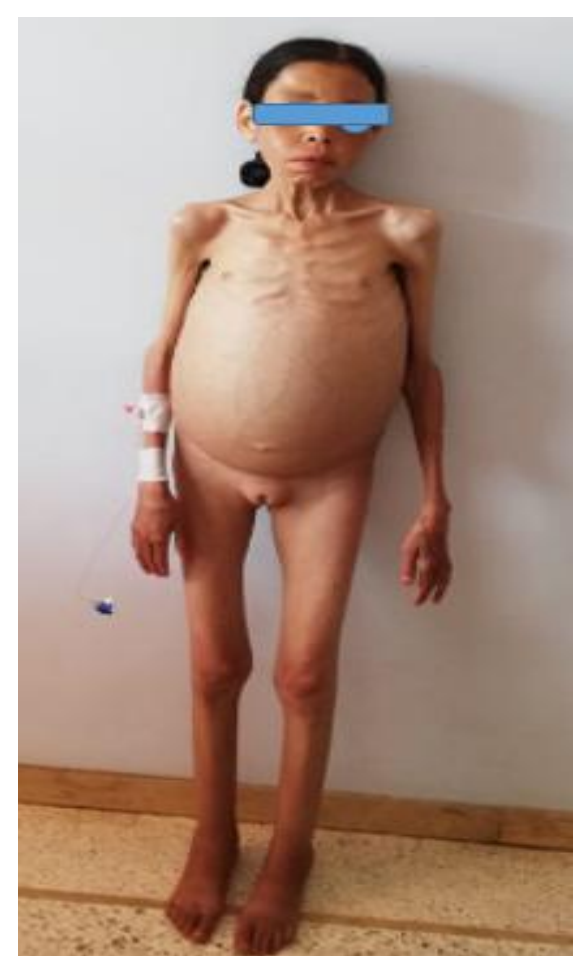

Initial laboratory investigations showed an abnormal liver profile, with aspartate aminotransferase $66 \mathrm{U} / \mathrm{L}$, alanine aminotransferase $73 \mathrm{U} / \mathrm{L}$, alkaline phosphatase $254 \mathrm{U} / \mathrm{L}$, gamma glutamyl-transpeptidase $113 \mathrm{U} / \mathrm{L}$, bilirubin $22 \mu \mathrm{mol} / \mathrm{L}$, albumin $24 \mathrm{~g} / \mathrm{L}$, prothrombin time $56 \%$, hemoglobin $102 \mathrm{~g} / \mathrm{L}$, leukocytes $3370 / \mathrm{L}$ and platelets $95 \times 10^{3} / \mathrm{L}$. Peritoneal fluid analysis was performad finding a clear transudate sterile fluid with few lymphocytes cells. An aetiological study was performed, showing a positive antimitochondrial antibody (AMA) level and an elevated immunoglobulin IgM. Serology negative for viral hepatitis (HBsAg and HCVantibodies) and anti-LKM1, antismooth muscle antibody, antinuclear antibody ANA and anti-SLA were normal. Liver ultrasound showed a heterogeneous liver with signs of portal hypertension, hypertrophy of the caudate lobe and large splenomegaly of $184 \mathrm{~mm}$, with ascites. Upper gastrointestinal endoscopy did show a grade I oesophageal varices with no features of portal gastropathy. She was prescribed ursodeoxycholic acid at a dose of $15 \mathrm{mg} / \mathrm{kg}$ body weight.

\section{DISCUSSION}

It is common for patients with Turner syndrome to have abnormal liver function test results, for various different reasons. Abnormal liver function results have traditionally been attributed to hepatic steatosis because of the higher incidence of obesity and diabetes in these patients but it was not the reason in our patient [2]. She was not overweight and did not have diabetes or dyslipidaemia, she had none of the associated factors. Several types of biliary involvement have been reported in the context of Turner syndrome, including sclerosing cholangitis, primary biliary
Fig-1

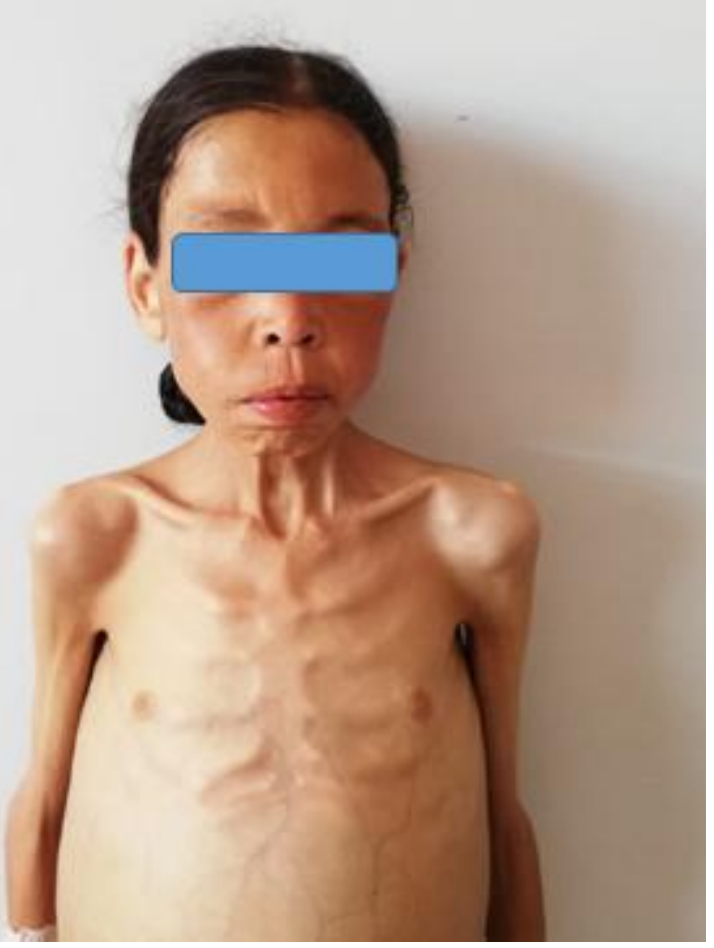

cirrhosis, bile duct paucity and biliary atresia. The frequency or prevalence of $\mathrm{PBC}$ in Turner syndrome has not been studied, although biliary involvement of Turner syndrome and PBC share similarities [3], and that cases of $\mathrm{PBC}$ have been reported in patients with Turner syndrome $[4,5]$. In both diseases, the frequency of cholestasis is increasing with age, and both diseases are strongly associated with autoimmune disorders. Autoimmunity is more frequent in Turner syndrome patients than in normal females [6] with, in particular, increased risk of developing autoimmune thyroid disease [7]. A recent study reported a significantly more frequent $\mathrm{X}$ chromosome monosomy in women with primary biliary cirrhosis than in controls matched for age. It was proposed that the $\mathrm{X}$ chromosome contains genes involved in immune tolerance, the functional loss of which would predispose the patients to a selftolerance breakdown and subsequent development of autoimmune diseases [8]. Systematic analysis of the presence of AMA has not been reported in the majority of clinical studies on patients with TS. However, TS and PBC share several similarities [9], both conditions are strongly associated with autoimmune disorders. Antithyroid antibodies are found in approximately $40 \%$ of patients with TS and more commonly in those who also have abnormal liver biochemistry [10]. It has also been demonstrated that as many as $78 \%$ of patients with TS have bile duct changes typically seen in small duct primary sclerosing cholangitis, a disease in which histology could be difficult to differentiate from PBC [11]. A recent report demonstrated that $\mathrm{X}$ chromosome monosomy occurred significantly more commonly in patients with PBC than in controls and patients with hepatitis. The authors suggest that the deficiency of genes localized to the $\mathrm{X}$ chromosome may predispose to 
altered immune responses, thus increasing the risk of PBC [11].

\section{Conclusion}

Because genetic predisposition to $\mathrm{PBC}$ has been supported by several reports [12], systematic studies, including autoimmune markers in cholestatic patients with Turner syndrome, may help in the elucidation of the etiology of PBC. The present case may support the importance of $\mathrm{X}$ chromosome genes in the development of genetic predisposition to PBC, and emphasizes the necessity for a systematic study.

\section{REFERENCES}

1. Gravholt $\mathrm{CH}$. Epidemiological, endocrine and metabolic features in Turner syndrome. Arq Bras Endocrinol Metabol, 2005; 49:145-56.

2. Roulot D. Liver involvement in Turner syndrome. Liver Int. 2013;33:24-30.

3. Milkiewicz P, Heathcote J. Can Turner syndrome teach us about the pathogenesis of chronic cholestasis? Hepatology. 2004; 40:1226-8.

4. Gómez AM, Cuenca CC, Ortiz VM, Monteoliva MJ, Gorostiza JR, Filgueia RJ. Association of primary biliary cirrhosis, Turner's syndrome and chronic myeloid leukemia. Gastroenterologia y hepatologia. 1997 Jan;20(1):44-45.

5. Milkiewicz P, Heathcote J. Primary biliary cirrhosis in a patient with Turner syndrome. Can J Gastroenterol, 2005; 19:631-3.
6. Elsheikh M, Dunger DB, Conway GS, Wass JA. Turner's syndrome in adulthood. Endocr Rev, 2002; 23:120-40.

7. Elsheikh M, Wass JA, Conway GS. Autoimmune thyroid syndrome in women with Turner's syndrome-the association with karyotype. Clin Endocrinol, 2001; 55: 223-6.

8. Miozzo M, Selmi C, Gentilin B, Grati FR, Sirchia S, Oertelt S, Zuin M, Gershwin ME, Podda M, Invernizzi P. Preferential X chromosome loss but random inactivation characterize primary biliary cirrhosis. Hepatology. 2007 Aug;46(2):456-62.

9. Milkiewicz P, Heathcote J. Can Turner syndrome teach us about the pathogenesis of chronic cholestasis? Hepatology. 2004; 40:1226-8.

10. Larizza D, Locatelli M, Vitali L, Vigano C, Calcaterra V, Tinelli C, Sommaruga MG, Bozzini A, Campani R, Severi F. Serum liver enzymes in Turner syndrome. European journal of pediatrics. 2000 Feb 1;159(3):143-8.

11. Roulot D, Degott C, Chazouilleres O, Oberti F, Cales P, Carbonell N, Benferhat S, BressonHadni S, Valla D. Vascular involvement of the liver in Turner's syndrome. Hepatology. 2004 Jan;39(1):239-47.

12. Jones DE, Donaldson PT. Genetic factors in the pathogenesis of primary biliary cirrhosis. Clin Liver Dis, 2003;7:841-64. 